\begin{tabular}{c}
\hline RECORDS OF PHARMACEUTICAL \\
AND BIOMEDICAL SCIENCES
\end{tabular}

\title{
Qualitative GC-MS analysis and antimicrobial activity of volatiles from Carthamus lanatus (L.) growing in Egypt
}

\author{
Rasha M. Abu El- Khair ${ }^{a^{*}}$, Mariam Y. Ghanem ${ }^{b}$, Gamal A. Omran ${ }^{\mathrm{c}}$, Ahmed A. Seif El-Din ${ }^{\mathrm{a}}$ \\ ${ }^{a}$ Department of Pharmacognosy, Faculty of Pharmacy, Alexandria University, Alexandria, Egypt \\ ${ }^{b}$ Department of Pharmacognosy, Faculty of Pharmacy, Damanhour University, Damanhour, Egypt \\ ${ }^{c}$ Department of Biochemistry, Faculty of Pharmacy, Damanhour University, Damanhour, Egypt
}

Received on: 19.08. 2019

Revised on: 26. 08. 2019

Accepted on: 28. 08. 2019

Correspondence Author:

Tel: $+20-1204411736$

E-mail address:

rasha.aboelkhair@alexu.edu.eg

\begin{abstract}
The volatiles of both fresh aerial parts and flowers of Carthamus lanatus L. plant growing in Egypt were isolated by hydro-distillation method. The obtained volatiles were subsequently subjected to qualitative analysis by GC-MS analysis, which in turn revealed the presence of 44 compounds. The interpretation of the isolated compounds depended on comparison of their mass spectra with those saved in instrument library, alongside the data reported in literature. On the other hand, a comparative investigation between the Egyptian and Bulgarian species was carried out, which in turn revealed great differences. Antimicrobial screening (using agar diffusion method) of the screened volatiles of Egyptian plant was also carried out, that labored into promising results of potent activity exhibited against different bacteria and fungi compared with gentamycin and ketoconazole antimicrobial standards.
\end{abstract}

Keywords: Carthamus lanatus, GC-MS, Asteraceae, Antimicrobial activity, agar diffusion method.

\section{Introduction}

Asteraceae is one of the largest and economically most important plant families. It is divided into eleven subfamilies and thirty-five tribes. Genus Carthamus is a well-known genus belongs to Asteraceae that composed of annual or perennial herbs or shrublets, usually spiny with homogamous capitula and compressed very hard achenes (Formisano et al., 2012). Carthamus lanatus L. is a biennial plant growing in the Mediterranean region (Hellwig, 2004). Previous studies on this plant revealed its importance due to presence of several different components of diverse chemical nature. Phytochemical studies showed the presence of flavonoids (El-Shaer et al., 1998; Novruzov and Shamsizade, 1998), sesquiterpenes glycosides (San Feliciano et al., 1990), lipids (Demir et al., 1978 ; Stefanov et al.,2003 ), aromatic acids (Lahloub et al.,1993), sterols, triterpenes and volatiles (Mitova et al.,2003). Recently, alkaloids, tannins and saponins were reported (Feroz and Ali.,2016).

The most important biological activities reported for Carthamus lanatus L. include antioxidant (Kancheva et al., 2007), analgesic, antiinflammatory (Bocheva et al., 2003; Jalil et al., 2003), sedative, antitumor (Benedi et al., 1986), 
antibacterial and antifungal activities (Taskova et al., 2002). Moreover, mitogenic effect (TopashkaAncheva et al., 2006) and clastogenic effect (Topashka-Ancheva. et al., 2003) were evaluated.

In 2003, a GC-MS study of the volatiles of the Bulgarian plant showed the presence of many volatile components (Mitova et al., 2003), however, to the best of our knowledge, no studies have been reported in literature concerning analysis of the volatile components of the Egyptian plant. Thus, the study in hand aimed, for the first time, to analyze the volatiles of Egyptian plant, compare its volatiles with that of the Bulgarian one, and to evaluate the antimicrobial activity of volatiles present.

\section{Experimental}

\subsection{Plant material and chemicals}

The aerial flowering parts of Carthamus lanatus (L.) were collected in June 2016 from Borg Al-Arab region, Alexandria, Egypt. The plant was used in fresh state. The plant was kindly identified by Prof. Dr. Ahmed A. Seif El-Din. Professor of Pharmacognosy, Department of Pharmacognosy, Alexandria University, Egypt. Solvents and chemicals were purchased from Merck, Dramstadt, Germany.

\subsection{Instruments}

GC-MS analysis was performed with Agilent Technologies 7890A gas chromatography system (Agilent, United States) linked to Agilent Technologies 5975C inert mass spectrometry detector provided with Agilent Mass Hunter ${ }^{\mathrm{TM}}$ Acquisition software (Agilent, United States).

\subsection{Isolation of volatile components}

Fresh flowers were separated from aerial parts, $80 \mathrm{~g}$ of flowers and $200 \mathrm{~g}$ of aerial parts were separately subjected to 4 hours hydro-distillation using simple distillation system. The hydro-distillation system consisted of $1 \mathrm{~L}$ distillation flask containing the plant material in distilled water, connected with a condenser and then a $500 \mathrm{~mL}$ receiving flask filled with around $50 \mathrm{~mL}$ diethyl ether where the volatiles were collected in the receiving flask.

\subsection{Gas Chromatography-Mass Spectro- metry analysis}

The GC-MS analysis was performed using Agilent Technologies 7890A gas chromatography system linked to Agilent Technologies 5975C inert mass spectrometry detector provided with Agilent Mass Hunter Acquisition software.

The GC system was equipped with Agilent Technologies 7693 auto-sampler (Agilent, United States), Agilent Technologies capillary column HP5MS (Agilent, United States) filled with 5\% phenyl methyl siloxane, $(30 \mathrm{~m} \times 0.25 \mathrm{~mm}$ I.D, $0.25 \mu \mathrm{m}$ film thickness).

Injector auto-sampler injected a volume of $1 \mu \mathrm{L}$ at $300{ }^{\circ} \mathrm{C}$. Helium gas was used as carrier gas with constant flow rate at $1.2232 \mathrm{~mL} \mathrm{~min}^{-1}$, column head pressure was 22.231 psi. Oven temperature was programmed starting by initial temperature $90^{\circ} \mathrm{C}$ for $1 \mathrm{~min}$ then increased by rate $8^{\circ} \mathrm{C} / \mathrm{min}$ to $205^{\circ} \mathrm{C}$ for $1 \mathrm{~min}$ then $5^{\circ} \mathrm{C} / \mathrm{min}$ to $250^{\circ} \mathrm{C}$ for $1 \mathrm{~min}$ and finally $8^{\circ} \mathrm{C} / \mathrm{min}$ to $300^{\circ} \mathrm{C}$ for $30 \mathrm{~min}$ so that the total run time was $61.875 \mathrm{~min}$. Electron energy was adjusted at $70 \mathrm{eV}$.

Identification of the peaks was carried out by matching their mass spectra with those present in Agilent Mass Hunter Acquisition software library. Further identification was achieved by comparing the data obtained with those reported in literature.

\subsection{Antimicrobial activity}

Antimicrobial and antifungal activities of the volatiles of both flowers and aerial parts of the plant were screened using the agar diffusion method according to guidelines of National Committee for Clinical Laboratory Standards (NCCLS), (2002). Samples were tested against Gram-positive bacteria (Staphylococcus aureus and Bacillus subtilis), Gram-negative bacteria (Escherichia coli and Klebsiella pneumoniae) and fungi (Candida albicans and Aspergillus flavus). Bacterial and fungal cultures were obtained from Microbiology Dpartment of Faculty of Medicine, (Demerdash Hospital), Ain Shams University, Cairo, Egypt. Ketoconazole and gentamicin were used as standards antimicrobial agents.

One $\mathrm{ml}$ of 24 hours broth culture of each tested organisms was separately inoculated into $100 \mathrm{ml}$ of sterile molten nutrient agar maintained at $45^{\circ} \mathrm{C}$. The inoculated medium was mixed well and poured into sterile $10 \mathrm{~cm}$ diameter Petri-dishes, receiving $15 \mathrm{~mL}$. Standards were weighed and dissolved up to concentration $20 \mathrm{mg} / \mathrm{ml}$ in DMSO; Then volume of $100 \mu \mathrm{L}$ of each of standard and the tested volatiles of both flowers and fresh aerial part were inserted in each well (6 $\mathrm{mm}$ diameter) followed by incubation at $37^{\circ} \mathrm{C}$ for 24 hours. 


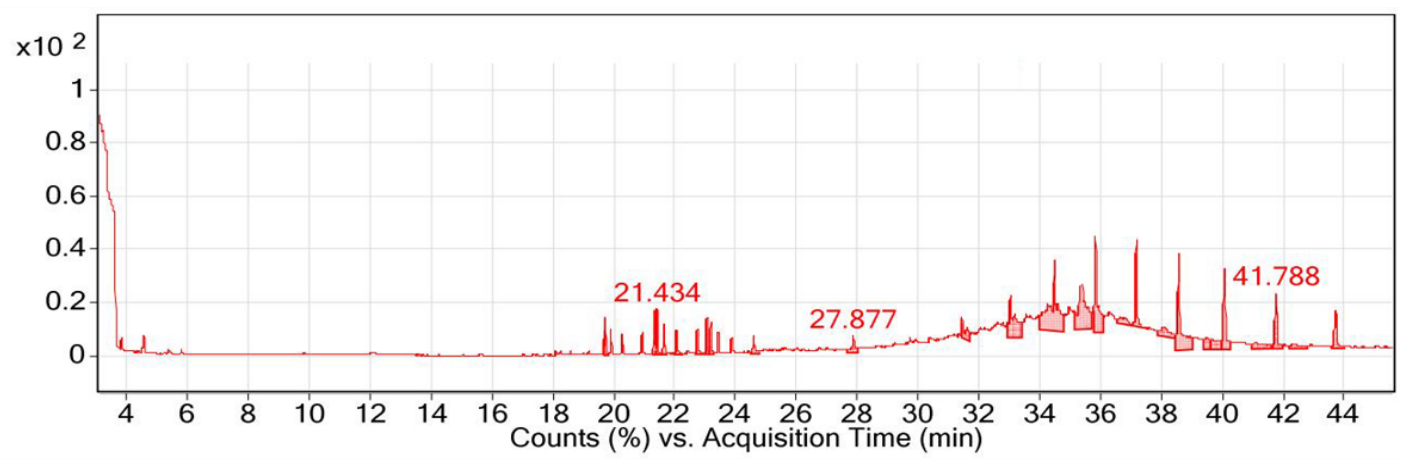

Figure 1: Gas chromatogram of Carthamus lanatus (L.) aerial parts

Table 1: Volatiles from Carthamus lanatus L. aerial parts

\begin{tabular}{|c|c|c|c|}
\hline Rt (min) & Compound name & Rt (min) & Compound name \\
\hline 15.610 & $\begin{array}{l}\text { Decanoic acid, 1,1a,1b,4,4a,5,7a,7b,8,9- } \\
\text { decahydro-4a,7b-dihydroxy-3- } \\
\text { (hydroxymethyl)-1,1,6,8-tetramethyl-5- } \\
\text { oxo-9aH-cyclopropa[3,4]benz[1,2- } \\
\text { e]azulene-9,9a-diyl ester, [1aR- } \\
(1 \mathrm{a} \alpha, 1 \mathrm{~b} \beta, 4 \mathrm{a} \beta, 7 \mathrm{a} \alpha, 7 \mathrm{~b} \alpha, 8 \alpha, 9 \beta, 9 \mathrm{a} \alpha)] \text { - }\end{array}$ & 23.079 & (1-Pentyloctyl)benzene \\
\hline 18.100 & (1-Butylhexyl)benzene & 23.204 & (1-Butylnonyl)benzene \\
\hline 18.250 & (1-Propylheptyl)benzene & 23.442 & (1-Propylheptadecyl) benzene \\
\hline 18.581 & Methyl 6,8-octadecadiynoate & 23.892 & (1-Ethylundecyl)benzene \\
\hline 19.000 & 8-Octadecenal & 24.611 & (1-Methyldodecyl)benzene \\
\hline 19.201 & (1-Methylnonyl)benzene & 27.877 & 1-(4-Bromobutyl)-2-piperidinone \\
\hline 19.663 & (1-Pentylhexyl)benzene & 31.467 & 1-Heptacosanol \\
\hline 19.720 & (1-Butylheptyl)benzene & 33.056 & $\begin{array}{l}\text { Octatriacontyl } \\
\text { pentafluoropropionate }\end{array}$ \\
\hline 19.907 & (1-Propyloctyl)benzene & 34.501 & 2-Octadecyloxyethanol \\
\hline 20.289 & (1-Ethylnonyl)benzene & 35.833 & 7-Hexylicosane \\
\hline 20.940 & (1-Methyldecyl)benzene & 37.191 & Heneicosane \\
\hline 21.346 & (1-Pentylheptyl)benzene & 38.117 & 17-Pentatriacontene \\
\hline 21.434 & (1-Butyloctyl)benzene & 38.573 & 2-Methylicosane \\
\hline 21.659 & (1-Propylnonyl)benzene & 40.081 & Octacosane \\
\hline 22.059 & (1-Ethyldecyl)benzene & 41.776 & Tetratetracontane \\
\hline 22.754 & (1-Methylundecyl)benzene & 43.740 & Heptacosane \\
\hline
\end{tabular}

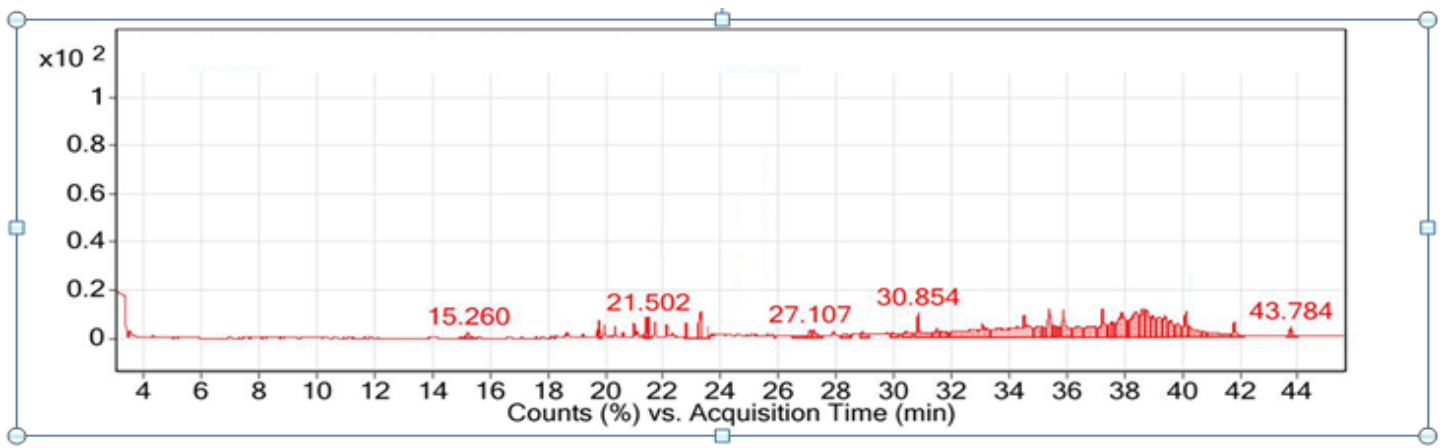

Figure 2: Gas chromatogram of Carthamus lanatus (L.) flowers 
Table 2: Volatiles from Carthamus lanatus L. flowers

\begin{tabular}{|c|c|c|c|}
\hline $\begin{array}{l}\text { Rt } \\
(\mathbf{m i n})\end{array}$ & Compound name & $\begin{array}{l}\mathbf{R t} \\
(\mathbf{m i n})\end{array}$ & Compound name \\
\hline 15.260 & $\begin{array}{l}\text { 6-(1-Hydroxymethylvinyl)-4,8a- } \\
\text { dimethyl-3,5,6,7,8,8a-hexahydro- } \\
\text { 1H-naphthalen-2-one }\end{array}$ & 22.822 & (1-Methylundecyl)benzene \\
\hline 19.238 & (1-Methylnonyl)benzene & 27.107 & $\begin{array}{l}\text { 2-[4-methyl-6-(2,6,6- } \\
\text { trimethylcyclohex-1-enyl)hexa-1,3,5- } \\
\text { trienyl]cyclohex-1-en-1- } \\
\text { carboxaldehyde }\end{array}$ \\
\hline 19.726 & (1-Pentylhexyl)benzene & 27.214 & $\begin{array}{l}\text { Propanoic acid, 2-methyl-, } \\
\text { (dodecahydro-6a-hydroxy-9a-methyl-3- } \\
\text { methylene-2,9-dioxoazuleno[4,5- } \\
\text { b]furan-6-yl)methyl ester, } \\
(3 \mathrm{a} \alpha, 6 \beta, 6 \mathrm{a} \alpha, 9 \mathrm{a} \beta, 9 \mathrm{~b} \alpha)]-\end{array}$ \\
\hline 19.964 & (1-Propyloctyl)benzene & 27.914 & tert-Hexadecanethiol \\
\hline 20.351 & (1-Ethylnonyl)benzene & 28.921 & $\begin{array}{l}\mathrm{N} \text {-(2-Methylbutyl)undeca-(2E,4E)- } \\
\text { diene-8,10-diynamide }\end{array}$ \\
\hline 20.614 & Aromadendrene oxide-(1) & 30.454 & 7-Methyl-Z-tetradecen-1-ol acetate \\
\hline 21.008 & (1-Methyldecyl)benzene & 30.848 & Tributyl acetylcitrate \\
\hline 21.102 & 3-ethyl-3-hydroxyandrostan-17-one & 33.081 & Ethanol, 2-(octadecyloxy)- \\
\hline 21.402 & (1-Pentylheptyl)benzene & 35.890 & 7-Hexylicosane \\
\hline 21.496 & (1-Butyloctyl)benzene & 37.253 & 2,6,10-Trimethyltetradecane \\
\hline 21.721 & (1-Propylnonyl)benzene & 40.143 & 2-Methyleicosane \\
\hline 22.128 & (1-Ethyldecyl)benzene & 41.820 & Tetratetracontane \\
\hline 22.322 & Columbin & 43.784 & Heptacosane \\
\hline
\end{tabular}

Table 3: Comparison between volatiles isolated from Egyptian and Bulgarian Carthamus lanatus $L$.

\begin{tabular}{|c|c|c|c|c|c|}
\hline Compound & $\mathbf{B}$ & $\mathbf{E}$ & Compound & $\mathbf{B}$ & $\mathbf{E}$ \\
\hline Hydrocarbons & & & Aromatics & & \\
\hline Heptacosane & + & + & (1-Methylnonyl)benzene & - & + \\
\hline Octacosane & + & + & (1-Pentylhexyl)benzene & - & + \\
\hline Heneicosane & + & + & (1-Propyloctyl)benzene & - & + \\
\hline 7-Hexylicosane & - & + & (1-Ethylnonyl)benzene & - & + \\
\hline 17-Pentatriacontene & - & + & (1-Methyldecyl)benzene & - & + \\
\hline 2-Methylicosane & - & + & (1-Pentylheptyl)benzene & - & + \\
\hline 2,6,10-Trimethyltetradecane & - & + & (1-Butyloctyl)benzene & - & + \\
\hline 2-Methyleicosane & - & + & (1-Propylnonyl)benzene & - & + \\
\hline 3-Tetradecen-5-yne & + & - & (1-Ethyldecyl)benzene & - & + \\
\hline Docosane & + & - & (1-Methylundecyl)benzene & - & + \\
\hline Tricosane & + & - & (1-Butylhexyl)benzene & - & + \\
\hline Tetracosane & + & - & (1-Propylheptyl)benzene & - & + \\
\hline Pentacosane & + & - & (1-Butylheptyl)benzene & - & + \\
\hline Hexacosane & + & - & (1-Pentyloctyl)benzene & - & + \\
\hline Nonacosaner & + & - & (1-Butylnonyl)benzene & - & + \\
\hline Triacontane & + & - & (1-Propylheptadecyl) benzene & - & + \\
\hline Hentriacontane & + & - & (1-Ethylundecyl)benzene & - & + \\
\hline Tetratetracontane & - & + & (1-Methyldodecyl)benzene & - & + \\
\hline Aldehydes and ketones & & & Toluene & + & - \\
\hline $\begin{array}{l}\text { 6-(1-Hydroxymethylvinyl)-4,8a-dimethyl- } \\
\text { 3,5,6,7,8,8a-hexahydro-1H-naphthalen-2-one }\end{array}$ & - & + & Benzene isocyanate & + & - \\
\hline Androstan-17-one, 3-ethyl-3-hydroxy-, (5a)- & - & + & $\begin{array}{l}\text { Phenol-4,6-di-(1,1-dimethyl ethyl)- } \\
\text { 2-methyl }\end{array}$ & + & - \\
\hline
\end{tabular}




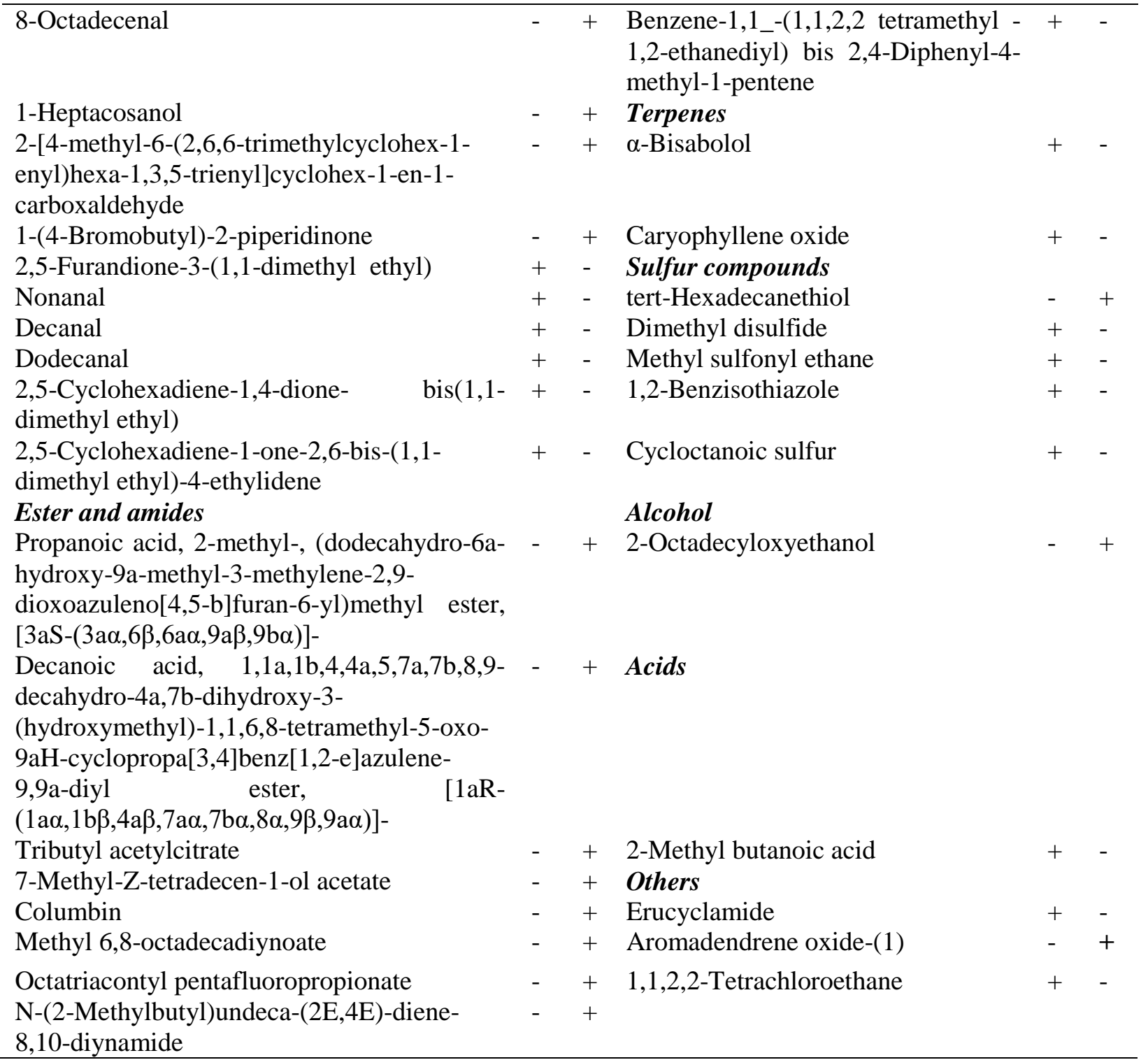

B: Bulgarian plant, E: Egyptian plant

The sensitivities were compared by measuring inhibition zones (in $\mathrm{mm}$ ) with those of standards.

\section{Results and discussion}

\subsection{Gas Chromatography-Mass Spectro- metry analysis}

The GC- MS qualitative analysis of volatiles yield by hydro-distillation of the fresh aerial parts of Cartahmus lanatus L. revealed the presence of 32 compounds, appeared in (Figure 1). These compounds belonged to different chemical classes (hydrocarbons, aldehydes and ketones, alcohols, esters, amides and different aromatic compounds). It is worth to mention that nine compounds were identified for the first time from genus Carthamus, namely, (1-Propyl-nonyl)benzene; (1-Ethyldecyl)benzene; (1-Methyl-dodecyl) benzene; 1Heptacosanol; Heneicosane; 2-Methylicosane; Octacosane; Tetratetracontane and Heptacosane.Moreover, twenty three of the revealed compounds were reported for the first time from family Asteraceae. Those compounds are: (1-Butylhexyl)benzene; Propylheptyl)benzene; Methyl 6,8-octadeca diynoate; 8-Octadecenal; (1-Methylnonyl) benzene; (1Pentylhexyl)benzene; (1-Butylheptyl)benzene; (1-Propyloctyl) benzene; (1-Ethylnonyl)benzene; (1-Methyldecyl)benzene; (1-Pentylheptyl) benzene; (1-Butyloctyl)benzene; (1-Methylundecyl)benzene; (1-Pentyloctyl)benzene; (1-Butylnonyl)benzene; (1-Propylheptadecyl) benzene; (1-Ethylundecyl) 
benzene; 1-(4-Bromobutyl)-2-piperidinone; Octatriacontyl pentafluoropropionate; 2-Octadecyloxyethanol; 7-Hexylicosane; 17-Pentatriacontene and Decanoic acid, 1,1a,1b,4,4a,5,7a,7b,8,9-decahydro4a,7b-dihydroxy-3-(hydroxymethyl)-1,1,6,8-tetramethyl-5-oxo-9aH-cyclopropa[3,4]benz[1,2e]azulene-9,9a-diyl ester, [1aR-(1a $\alpha, 1 \mathrm{~b} \beta, 4 \mathrm{a} \beta, 7 \mathrm{a} \alpha$, $7 \mathrm{~b} \alpha, 8 \alpha, 9 \beta, 9 \mathrm{a} \alpha)]$. The chemical composition of the volatiles of fresh aerial parts of Cartahmus lanatus L. are summarized in (Table 1).

Qualitative analysis the fresh flowers' volatiles showed the presence of 26 compounds of the same chemical classes as those present in the aerial parts (Figure 2). In addition, for the first time in lanatus species, three new compounds were figured out by this qualitative analysis: aromadendrene oxide; 3-ethyl-3- hydroxyandrostan-17-one and 7Methyl-Z-tetradecen-1-ol acetate. Meanwhile, for the first time in genus Carthamus, eight compounds were reported:(1-Propylnonyl)benzene; (1Ethyldecyl)benzene; tert-Hexadecanethiol; N-(2Methylbutyl)undeca-(2E,4E)-diene-8,10-diynamide; 2,6,10-Trimethyltetradecane; 2-Methyleicosane; Tetratetracontane and Heptacosane. It is worth mentioning that, fifteen compounds were reported from family Asteraceae for the first time. Those are 6-(1-Hydroxymethylvinyl)-4,8a-dimethyl-

3,5,6,7,8,8a-hexahydro-1H-naphthalen-2-one; (1Methylnonyl) benzene; (1-Pentylhexyl)benzene; (1Propyloctyl)benzene; (1-Ethylnonyl)benzene; (1Methyldecyl)benzene; (1--Pentylheptyl)benzene; (1-Butyloctyl)benzene; Columbin; (1Methylundecyl)benzene; 2-[4-methyl-6-(2,6,6trimethylcyclohex-1-enyl)hexa-1,3,5-

trienyl]cyclohex-1-en-1-carboxaldehyde; Propanoic acid, 2-methyl-, (dodecahydro-6a-hydroxy-9amethyl-3-methylene-2,9-dioxoazuleno[4,5-b]furan6-yl)methylester, [3aS $(3 \mathrm{a} \alpha, 6 \beta, 6 \mathrm{a} \alpha, 9 \mathrm{a} \beta, 9 \mathrm{~b} \alpha)]$;

Tributyl acetylcitrate; Ethanol, 2-(octadecyloxy) and 7-Hexylicosane. The chemical composition of the volatiles of fresh flowers of Cartahmus lanatus L. are summarized in (Table 2).

\subsection{Comparative study between volatiles isolated from Egyptian and Bulgarian Carthamus lanatus $\mathbf{L}$.}

When it comes to the second comparative part of the study, it was easily observed that, there is a great difference between the volatiles' composition between the Egyptian Carthamus lanatus and the Bulgarian one. Only three compounds were in common between the two plants which were heptacosane, octacosane and heneicosane. Analysis of the obtained results showed that the volatiles composition of Egyptian plant was richer in ester and aromatic compounds, while that of the Bulgarian one was richer in hydrocarbons. The composition of the volatiles of both plants is summarized in (Table 3).

\subsection{Antibacterial and Antifungal activities of volatiles}

The biological screening of the volatiles of fresh aerial parts of Egyptian Carthamus lanatus revealed a potent antifungal activity against Candida albicans, even more potent than ketoconazole antifungal drug, but only a moderate antifungal activity against Aspergillus flavus. Regarding the antibacterial activity, the volatiles showed moderate activity against Bacillus subtilis only, with no activity against methicillin resistant Staphylococcus aureus (MARSA), E.coli and $K$. pneumonia. Gentamycin was used as reference standard antibacterial drug.

The antimicrobial activity results of volatiles of the fresh flowers showed potent antibacterial activity against MARSA, E.coli and $K$. pneumonia compared with gentamycin, while they showed moderate activity against Bacillus subtilis. The volatiles also showed good antifungal activity against both Candida albicans and Aspergillus flavus. The results of antimicrobial activity studies are summarized in (Table 4).

Table 4: Antimicrobial activity of volatiles from Carthamus lanatus $\mathbf{L}$.

\begin{tabular}{|l|c|c|c|c|}
\hline \multicolumn{5}{|c|}{ Diameter of inhibition zone (mm) } \\
\hline Pathogenic microorganism & Flower part & Aerial Part & Ketoconazole $^{\mathbf{a}}$ & Gentamycin $^{\mathbf{b}}$ \\
\hline Bacillus subtilis & 12 & 9 & N.A & 26 \\
\hline Staphylococcus aureus (MARSA) & 19 & N.A & N.A & 24.1 \\
\hline Klebsiella pneumoniae & 20 & N.A & N.A & 21 \\
\hline Escherichia Coli & 25 & N.A & N.A & 23 \\
\hline Candida albicans & 18 & 24 & 20.3 & N.A \\
\hline Aspergillus flavus & 15 & 8 & 17.1 & N.A \\
\hline
\end{tabular}

${ }^{\mathrm{a} A n t i f u n g a l ~ s t a n d a r d,}{ }^{\mathrm{b}}$ Antibacterial standard 


\section{Conclusion}

The obtained results from GC-MS analysis of the volatiles isolated from Egyptian Carthamus lanatus L. were remarkably different than those of the Bulgarian plant, with the appearance of 28 compounds for the first time from family Asteraceae, 12 compounds reported for the first time from genus Carthamus, in addition to the

\section{References}

Benedi, J., Iglesias, I., Manzanares, J., Zaragoza, F., 1986. Preliminary pharmacological studies of Carthamus lanatus L.. Plant Med. Phytother., 20, 25-30.

Bocheva, A., Mikhova, B., Taskova, R., Mitova, M., Duddeck, H., 2003. Antiinflammatory and analgesic effects of Carthamus lanatus aerial parts. Fitoterapia, 74(6), 559-563.

Demir, L., Nedim, A., Marquard, R., 1978. The fatty acid pattern and tocopherol content as different characteristics of Carthamus species found in Turkey. Ange Bot., 52 (5-6), 313-319.

El-Shaer, N., Shaaban, E., Abou-Karam, M., El-Din A., 1998. Flavonoids from Carthamus lanatus. Alex. J. Pharm. Sci., 12, 23-26.

Feroz, S., Ali, J., 2016. Preliminary phytochemical analysis, antioxidant, and antimicrobial evaluation of Carthamus lanatus. Innovare journal of sciences, 4(5), 1-3.

Formisano, C., Rigano, D., Senatore, F., Bancheva, S., Maggio, A., Rosselli, S., Bruno, M., 2012. Flavonoids in Subtribe Centaureinae (Cass.) Dumort. (Tribe Cardueae, Asteraceae): Distribution and ${ }^{13} \mathrm{C}$-NMR Spectral Data. Chemistry \& biodiversity, 9(10), 2096-2158.

Hellwig, FH. , 2004. Centaureinae (Asteraceae) in the Mediterranean-history of ecogeographical radiation. Plant Systematics and Evolution, 246(34), 137-162.

Jalil, S., Mikhova, B., Taskova, R., Mitova, M., Duddeck, H., Choudhary, M. I., 2003. In vitro Antiinflammatory Effect of Carthamus lanatus $L$. Zeitschrift für Naturforschung C, 58(11-12), 830832.

Kancheva, V., Taskova, R., Totseva, I., Handjieva, N., 2007. Antioxidant activity of extracts, fractions appearance of 3 compounds from lanatus species for the first time. Further studies are needed to justify those huge differences between the Egyptian and the Bulgarian Carthamus lanatus L. The antimicrobial screening of the volatiles isolated against different types of bacteria and fungi suggested the use of the volatiles of Egyptian plant as a promising antimicrobial candidate drug.

and flavonoid constituents from Carthamus lanatus L. Rivista italiana delle sostanze grasse, 84(2), 7786.

Lahloub, M., Amor, M., El-Khajaat, S., Haraz, F., 1993. A new serotonin derivative from seeds of Carthamus lanatus L. Mans. J. Pharm. Sci., 9, 234243.

Mitova, M., Taskova, R., Popov, S., Berger, R. G., Krings, U., Handjieva, N., 2003. GC/MS analysis of some bioactive constituents from Carthamus lanatus L. Zeitschrift für Naturforschung C, 58 (910), 697-703.

Novruzov, E. N., Shamsizade, L. A., 1998. Anthocyans of Carthamus species. Chemistry of natural compounds, 34(4), 514-515.

San Feliciano, A, Medarde, M, Del Rey, B, Del Corral, J., Barrero A.,1990. Eudesmane glycosides from Carthamus lanatus. Phytochemistry, 29(10), 3207-3211.

Stefanov, K, Taskova, R, Mitova, M, Topashka, M, Seizova, K., Duddeck, H., 2003. Analysis and biological activity of the lipid extract of Carthamus lanatus L. Comptes Rendus de l'Academie Bulgare des Sciences, 56(9), 9-13.

Taskova, R., Mitova, M., Najdenski, H., Tzvetkova, I., Duddeck, H., 2002. Antimicrobial activity and cytotoxicity of Carthamus lanatus. Fitoterapia, 73(6), 540-543.

Topashka-Ancheva, M, Taskova, R, Handjieva, N, Mikhova, B. Duddeck, H., 2003. Clastogenic effect of Carthamus lanatus L.(Asteraceae). Zeitschrift für Naturforschung C, 58(11-12), 833-836.

Topashka-Ancheva, M., Taskova, R., Handjieva, N., 2006. Mitogenic effect of Carthamus lanatus extracts, fractions and constituents. Fitoterapia, 77(7-8), 608-610 